\title{
Three-Dimensional Finite Element Analysis of Mixed Adhesive Bonded Joints under In-Plane Shear Loading
}

\author{
M.U. UYSAL* \\ Yildiz Technical University, Department of Mechanical Engineering, 34349 Istanbul, Turkey
}

\begin{abstract}
The main objective of this work is to evaluate the buckling capacity of a mixed adhesively lab joint panel when subjected to in-plane shear loading. In the plate joints, two types of adhesive were used in the overlap region and the stiff adhesive was located in the middle. This technique proposes to modify the mechanical properties of adhesive along the overlap. The adherents used in the investigation are made up from homogeneous isotropic material and laminated composite. Three-dimensional finite element models were developed for mixed adhesively bonded isotropic and orthotropic panel pairs. Linear finite element models have been developed to understand how variable modulus bond line affected the buckling loads. Finite element analyses were performed to predict buckling loads for different adhesive Young's modulus ratios and different adherent material types in the first five modes.
\end{abstract}

DOI: 10.12693/APhysPolA.129.448

PACS/topics: $62.20 . \mathrm{mq}$

\section{Introduction}

Adhesively joint strength optimization can be obtained through modification of the adhesive structure such as mixed adhesive bonded joints. Mixed modulus adhesive bonded joints have been proposed in the literature $[1,2]$ to improve the stress distribution and increase the performance of the joints. This technique consists in using stiff/strong adhesive in the middle of the overlap and flexible/ductile adhesive at the end of the overlap [3, 4]. Da Silva and Adams [5] and da Silva and Lopes [6] showed that the mixed adhesive technique gives more uniform stress distribution that is leads to strength increases in relation to a stiff adhesive alone. Fitton and Broughton [7] studied experimental and finite element analysis (FEA) with mixed adhesive method for improvement the joint performance. Adhesively bonded joints performance can be also change under the in-plane shear loading. In literature, Kim and Kedward [8] developed analytical solution for the stress analysis of an adhesively bonded lap joint under in-plane shear loading. Mocibob and Crisinel [9] presented glass panel behavior subjected in plane shear loading in architecture area. Also most recently, an interesting work on the adhesively bonded structures having graded properties under in plane shear loading can be found in [10].

The main objective of the present work is to assess how the buckling load of the mixed adhesive joints varies when different adhesive Young's modulus ratios are used at the joint under in-plane shear loading. Also, finite element analysis is used to predict buckling loads for mixed adhesive lap joints having both isotropic and orthotropic adherent materials.

*e-mail: mineuslu@yildiz.edu.tr

\section{Description of the mixed adhesively lap joint}

The geometry and dimensions of the mixed adhesively bonded plate are shown in Fig. 1a. The adherent plate

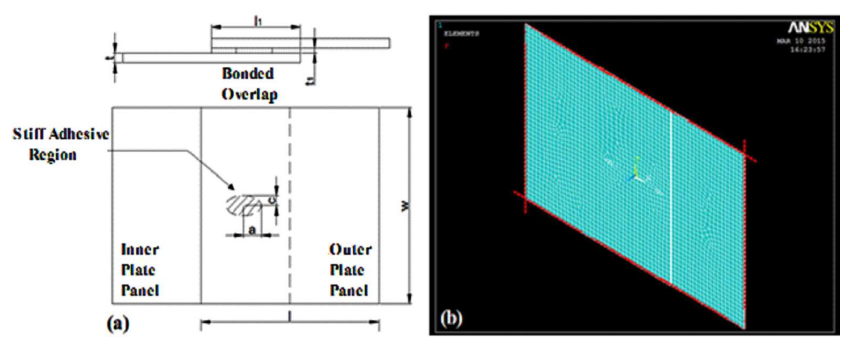

Fig. 1. Adhesively lap joint assembly: (a) geometry,

(b) finite element model under in-plane shear loading.

width $(w)$ and the adherent length $(l)$ are $100 \mathrm{~cm}$ and the adherent thickness $(t)$ is $0.5 \mathrm{~cm}$. Also in the joint structure bond length $\left(l_{1}\right)$ is chosen as $50 \mathrm{~cm}$. The stiff adhesive is located in the middle of the flexible adhesive layer and all adhesive layer thicknesses $\left(t_{1}\right)$ are $0.25 \mathrm{~cm}$. To obtain more general results from the analysis, the geometric shape of the stiff adhesive region is elliptically taken and the ratio of the minor axis to the major axis $(c / a)$ was taken equal to 0.1. The ratio of the stiff adhesive elastic modulus $\left(E_{1}\right)$ to flexible adhesive elastic modulus $\left(E_{2}\right)$ are varied as $E_{1} / E_{2}=50,100,250,1000$. Therefore, five different adhesive layer configurations were investigated. Additionally, the full flexible adhesive without stiff adhesive region was described as $E_{1} / E_{2}=1$. Adherents materials were chosen isotropic and orthotropic material and the mechanical properties of adherents and adhesives can be seen in Table I.

\section{Analysis of mixed adhesively lap joint}

Three-dimensional finite element analyses were performed using ANSYS $^{\circledR}$ commercial finite element 
TABLE I

Mechanical properties of adherent and adhesive [11].

\begin{tabular}{c|c|c|c}
\hline \hline & $\begin{array}{c}\text { Adherent } \\
\text { isotropic }\end{array}$ & $\begin{array}{c}\text { Adherent orthotropic } \\
\text { (woven fabric 0/90 laminates) }\end{array}$ & $\begin{array}{c}\text { Flexible adhesive } \\
\text { (loctite-hysol 9464) }\end{array}$ \\
\hline $\begin{array}{c}\text { Mechanical } \\
\text { Properties }\end{array}$ & $\begin{array}{c}E=22.00 \mathrm{GPa} \\
v=0.25\end{array}$ & $\begin{array}{c}E_{11}=E_{22}=22.00 \mathrm{GPa} ; E_{33}=9.00 \\
G_{12}=5.3 \mathrm{GPa} ; G_{23}=G_{13}=3.1 \mathrm{GPa} \\
F_{1 t}=F_{2 t}=350 \mathrm{MPa} ; F_{6}=95 \mathrm{MPa}\end{array}$ & $\begin{array}{c}E=1.78 \mathrm{GPa} \\
v=0.376\end{array}$ \\
\end{tabular}

analysis software. The numerical models were divided into finite number of elements using twenty-node solid elements (Solid 95) and in-plane shear load $1 \mathrm{~kg}$ was applied as seen in Fig. 1b. The contact surfaces between the stiff adhesive/flexible adhesive (Fig. 2a) and the adherents/adhesive (Fig. 2b) were modeled using surface to surface contact elements (Conta 174 and Targe 170). Thus, the contact problem can be considered to model the interface as two surfaces. These contact elements' positions can be seen in Fig. 2. Sliding and debonding of two surfaces were not considered and bonded always options in ANSYS ${ }^{\circledR}$ was chosen for contact surfaces. Also, penalty method was selected as contact algorithm and normal stiffness factor was considered to controlling penetration and optimal converge rate.
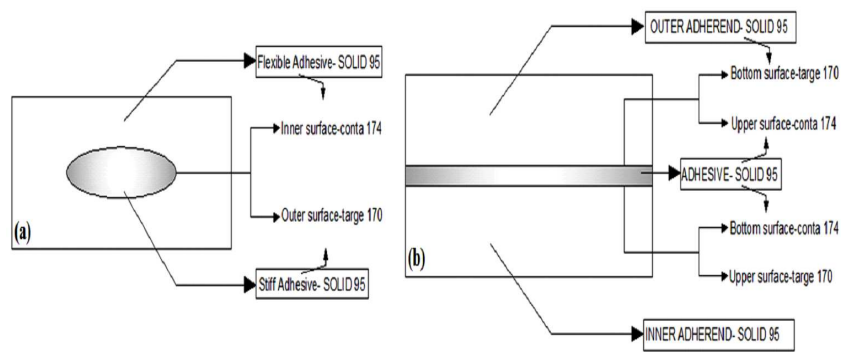

Fig. 2. Modeling of contact surfaces: (a) stiff-flexible adhesive contact, (b) adhesive-adherent contact.

\section{Analysis results and discussion}

The influences of the stiff/flexible adhesive elastic modulus ratio $\left(E_{1} / E_{2}\right)$ on the buckling load are presented in Fig. 3 and Fig. 4. Figure 3 shows that the critical buckling load (on mode 1) increased with increase of the $E_{1} / E_{2}$ ratio, because of occurring high strength in the adhesively lap joint. But this increase varies to the ranges of the elastic modulus ratio. When the ratio of $E_{1} / E_{2}$ is in between 1 and 50 , the critical buckling loads tend to drastically increase. When $E_{1} / E_{2}$ is in between 50 and 250, the critical buckling loads increase slightly. The similar curves are seen in the mixed adhesively lap joint having both orthotropic adherents and isotropic adherents as seen in Fig. 3a and b.

In addition, isotropic material selection for adherents gave better results than the orthotropic material on assemblies subjected to in-plane shear loading. When the

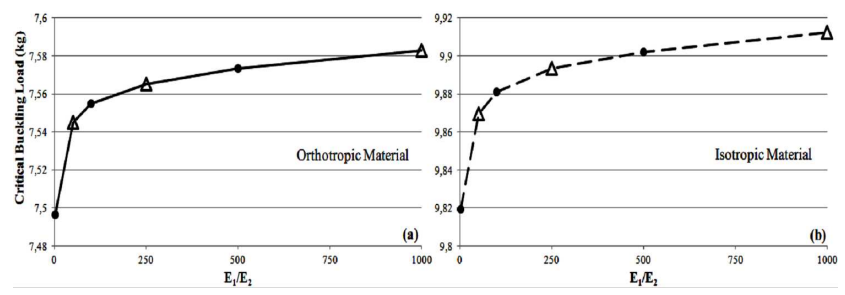

Fig. 3. Effects of the adherent material in the mixed adhesively lap joint: (a) orthotropic and (b) isotropic materials.

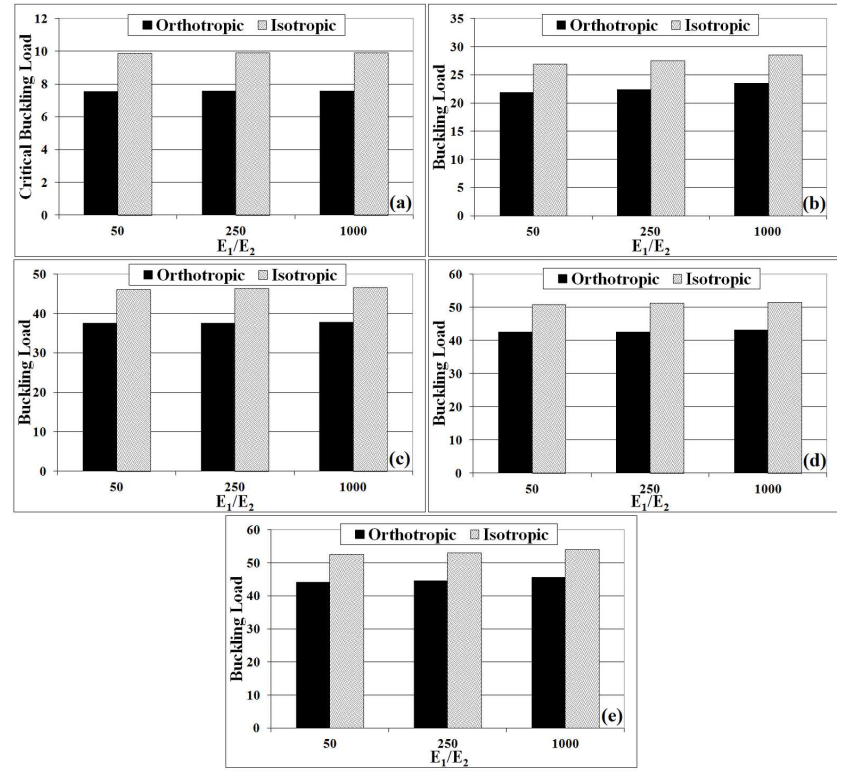

Fig. 4. Effects of the mixed adhesive elastic modulus ratio $\left(E_{1} / E_{2}\right)$ on the buckling load: (a) mode 1 , (b) mode 2 , (c) mode 3, (d) mode $4,($ e) mode 5.

adherent materials are compared for the first mode, the critical buckling load value was $7.49 \mathrm{~kg}$ for orthotropic adherents and this value was $9.82 \mathrm{~kg}$ for isotropic adherents, for $E_{1} / E_{2}$ is equal to 1 . This result and trends in Fig. 3 presented that the critical buckling load is increased nearly by $30 \%$ when orthotropic adherent material changed to isotropic adherents.

The results were summarized for the according mode numbers. The ratio of the adhesive elastic modulus $\left(E_{1} / E_{2}\right)$ in the mixed adhesively lap joints was compared with the first five modes. In Fig. 4, the buckling loads can be seen to be highly dependent on the 
ratio of $E_{1} / E_{2}$ for all modes, especially mode 2 . As seen in Fig. 4, the buckling load increased by $7.52 \%$ when the $E_{1} / E_{2}$ ratio increased from 50 to 1000 for the mixed adhesively joint having orthotropic adherents. This increment was calculated as $6.22 \%$ for the mixed adhesively isotropic adherents joint. These results presented that, as is known, $E_{1} / E_{2}$ ratio is affected by the buckling load, but also buckling load changing ratio should be handled with caution according to the mode numbers and adherents materials.

For full adhesively flexible adhesive case $\left(E_{1} / E_{2}=1\right)$, the buckling load increased 1.83 times in between mode 1 (Fig. 4a) and mode 2 (Fig. 4b) for orthotropic adherents and 1.65 times for the isotropic adherents. These increment values between mode 1 and mode 3 (Fig. 4c) were 4.01 times and 3.66 times for orthotropic and isotropic adherents, respectively. When the increment values between mode 1 and mode 4 (Fig. 4d) were considered for orthotropic and isotropic adherents, these values were determined as 4.57 times and 4.09 times, respectively. Besides, these values were obtained 4.85 times and 4.32 times for orthotropic and isotropic adherents as regarding the relation between mode 1 and mode 5 (Fig. 4e). When the elastic modulus ratio $\left(E_{1} / E_{2}\right)$ was selected as 1000, buckling load increased 2.1 times on between mode 1 and mode 2 for orthotropic adherents and this value was 1.88 for isotropic adherents. This increment ratio of buckling load in between mode 1 and mode 5 was 5.00 times and 4.45 times for orthotropic and isotropic adherents, respectively. These numeric results revealed that orthotropic material properties of the adherents play higher role than the isotropic material properties on buckling loads changing ratio according to mode numbers.

\section{Conclusion}

This study was performed in order to evaluate the buckling loads of mixed adhesively lap joints under inplane shear loading. In adhesively lap joint model, isotropic and orthotropic adherents were bonded with the adhesive layer having the stiff adhesive in the middle and the flexible adhesive around it. The ratios of the stiff adhesive elastic modulus to the flexible adhesive elastic modulus $\left(E_{1} / E_{2}\right)$ effects were investigated on the buckling loads for first five modes. Comparing the obtained results from numerical investigation, it is seen that the buckling load increases with increase of the $E_{1} / E_{2}$ as is known but the behaviour of the increment varies to range of the $E_{1} / E_{2}$. Also, the results presented that orthotropic adherents plays higher role on buckling loads changing ratio according to mode numbers than isotropic adherents. Therefore, in a mixed adhesively lap joint under in-plane shear loading, buckling load changing ratio should be handled with caution according to the mode numbers and adherents materials types.

\section{References}

[1] S. Semerdjiev, Metal to Metal Adhesive Bonding, Business Books Ltd, UK 1970.

[2] R.L. Patrick, Treatise on Adhesion and AdhesiveStructural Adhesives with Emphasis on Aerospace Applications, Marcel Dekker, New York 1976.

[3] E.A.S. Marques, L.F.M. da Silva, J. Adhesion 84, 917 (2008).

[4] P.J.C. das Neves, L.F.M. da Silva, R.D. Adams, J. Adhes. Sci. Technol. 23, 1 (2009).

[5] L.F.M. da Silva, R.D. Adams, Int. J. Adhes. Adhes. 27, 216 (2007).

[6] L.F.M. da Silva, M.J.C.Q. Lopes, Int. J. Adhes. Adhes. 29, 509 (2009).

[7] M.D. Fitton, J.G. Broughton, Int. J. Adhes. Adhes. 25, 329 (2005).

[8] H. Kim, K.T. Kedward, J. Adhesion 76, 1 (2001).

[9] D. Mocibob, M. Crisinel, in: Proc. Challenging Glass: Conference on Architectural and Structural Applications of Glass, Eds.: F. Bos, Ch. Louter, F. Veer, IOS Press, Delf 2007, p. 253.

[10] M.U. Uysal, U. Güven, Compos. Struct. 121, 182 (2015).

[11] O.E. Canyurt, C. Meram, M. Uslu, Int. J. Adhes. Adhes. 30, 281 (2010). 